is for those without. Oral hygiene is equally important for patients with or without dental implants as is attention to diet. But in my experience peri-implant infection is much less common than periodontal disease, and significantly implants do not suffer from root caries which is a large part of the problem of the ageing dentition and which is why your correspondent is seeing teeth decayed to roots around sound implant supported restorations. The logical conclusion is to provide more implant supported restorations not fewer.

I am unsure as to what D. Howarth is referring when he writes of restorative jewellery but I presume he is implying that dental implants are provided for cosmetic reasons. Virtually all dentistry has an aesthetic component but in my experience many more implants are placed for functional reasons than for purely aesthetic reasons. I am sure no dentist would deprive a patient of the huge benefits, possibly over many years, of implants used to retain full lower dentures, which have no aesthetic value at all. Even in a case with a high aesthetic component, such as replacement of a single central incisor, it is difficult to imagine persuading a 20-year-old that the advantages of implant replacement over the alternatives are outweighed by the prospect of possible maintenance difficulties 60 years or more in the future.

Many elderly patients will present in the future with not just implant supported restorations but also complex tooth supported restorations and the oral care for either should be very similar. The treatment planning for these patients earlier in life should include both where appropriate.

The answer to the problem is not to use fewer implants but to lobby for better oral care for the elderly and to try to preserve both natural and restored dentition whether implant or tooth supported. The only alternative is to resort to full clearances and full dentures which I am sure no dentist would like to see again.

K. Gibney

Southport

DOI: 10.1038/sj.bdj.2013.334

\section{IMPROVING STEADILY}

Sir, the 2009 Adult Dental Health Survey (ADHS) is the fifth in a series of national dental surveys that have been carried out every ten years since 1968 . It covers the adult population in England, Wales and Northern Ireland. Since Scotland decided not to participate in the ADHS 2009, it has been impossible to make any UK wide comparisons. ${ }^{1}$

Bespoke analyses, however, were carried out across a small number of measures using the data from the ADHS 2009 and the Scottish Health Survey (SHeS) in $2008^{2}$ and 2009. ${ }^{3}$ These comparisons were recorded on Excel spreadsheets which can be accessed from the Health and Social Care Information Centre website. ${ }^{4}$

In 1972, the level of total tooth loss among the Scottish population was $44 \% .{ }^{5}$ By the time of the SHeS 2009, the figure for this population had dropped to $12 \% .^{3}$ Nevertheless this figure for Scotland ${ }^{3}$ is still worse than those for the rest of the UK (England 6\%, Wales $10 \%$, Northern Ireland 7\%). ${ }^{4}$

In Scotland, the target of the 2005 Dental Action Plan was that 90\% of all adults would possess some natural teeth by $2010 .{ }^{6}$ The SHeS reports in $2010^{7}$ and $2011^{8}$ noted that the proportion of all adults possessing some natural teeth was $89 \%$ and $90 \%$ respectively. This means that the Scottish target has been met in 2011.

In $2009,71 \%$ of the adult population in Scotland had 20 or more natural teeth. ${ }^{3}$ Compared to the rest of the UK, this figure ${ }^{3}$ is also lower (England 81\%, Wales 73\%, Northern Ireland 77\%). ${ }^{4}$ Subsequent SHeS reports have shown that the percentage of all adults with 20 or more natural teeth increased by one percentage point each year, from 72\% in $2010^{7}$ to $73 \%$ in $2011 .^{8}$

This implies that oral health has improved steadily for the adult population in Scotland. A greater proportion of adults has now retained their teeth and maintained a minimum functional dentition. These could be attributed to the following key initiatives in Scotland:

- Development of oral health promotion programmes

- Introduction of free dental checks for adults
- Changes to the structure of dental services for adults including extending dental registration

- Opening of a new dental school in Aberdeen, and steps to attract more dental professionals to work in Scotland.

\section{A. Yeung}

Bothwell

1. Steele J G, Treasure E T, O'Sullivan I, Morris J, Murray J J. Adult Dental Health Survey 2009: transformations in British oral health 1968-2009. Br Dent J 2012; 213: 523-527.

2. Miller M. Dental health. In Bromley C, Bradshaw P, Given L (eds). The Scottish Health Survey 2008 Volume 1: Main Report.pp 37-53. Edinburgh: Scottish Government, 2009

3. Dobbie F. Dental health. In Bromley C, Given L, Ormston R (eds). The Scottish Health Survey 2009 Volume 1: Main Report. pp 59-77. Edinburgh: Scottish Government, 2010.

4. Health and Social Care Information Centre. Adult Dental Health Survey 2009 - summary report and thematic series. www.ic.nhs.uk/catalogue/ PUB01086

5. Todd J E, Whitworth A. Adult dental health in Scotland 1972. London: HMSO, 1974.

6. Scottish Executive. An action plan for improving oral health and modernising NHS dental services in Scotland. Edinburgh: Scottish Executive, 2005.

7. Given L. Dental health. In Bromley C, Given L (eds). The Scottish Health Survey 2010 Volume 1: Main Report. pp 43-53. Edinburgh: Scottish Government, 2011.

8. Rutherford L. Dental health. In Rutherford L, Sharp C, Bromley C (eds). The Scottish Health Survey 2011: Volume 1 - Adults. pp 48-62. Edinburgh: Scottish Government, 2012

DOI: $10.1038 / s j . b d j .2013 .335$

\section{LACK OF ATTENTION}

Sir, I wanted to comment about the letter from K. Parker and J. Patel (BDJ 2013; 214: 93-94). The comments I would wish to make are a) the tooth in question is clearly a lower right seven (not a six as stated) and (b) had the post been placed inside a healthy distal root of a restorable permanent second molar tooth its length and diameter would probably have been acceptable. This case clearly illustrates not the importance of using a correctly sized post, but inadequate knowledge of dental anatomy and a woeful lack of attention to detail by all concerned.

\section{K. F. Mills} By email DOI: 10.1038/sj.bdj.2013.336

The $B D$ J website now includes a facility enabling readers to immediately comment on letters. All comments must comply with the nature.com Terms and Conditions and Community Guidelines visit the $B D J$ website to find out more and to post your comment now. 